\title{
Erratum to: A Remote Mode Master Degree Program in Sustainable Energy Engineering: Student Perception and Future Direction
}

\author{
Udalamattha Gamage Kithsiri, \\ Ambaga Pathirage Thanushka Sandaruwan Peiris, \\ Tharanga Wickramarathna, Kumudu Amarawardhana, \\ Ruchira Abeyweera, Nihal N. Senanayake, Jeevan Jayasuriya, \\ and Torsten H. Fransson
}

\author{
Erratum to: \\ Chapter "A Remote Mode Master Degree Program \\ in Sustainable Energy Engineering: Student Perception \\ and Future Direction" in: M. E. Auer et al. (eds.), \\ Teaching and Learning in a Digital World, \\ Advances in Intelligent Systems and Computing 715, \\ https://doi.org/10.1007/978-3-319-73210-7_79
}

In the original version of this book, the second author's name has been updated from "Amagaha Pathirage Thaushka Sandaruwan Peiris" to "Ambaga Pathirage Thanushka Sandaruwan Peiris" in Chapter 79, which is a belated correction. The erratum chapter and the book have been updated with the change.

The updated online version of this chapter can be found at https://doi.org/10.1007/978-3-319-73210-7_79 